\title{
Application Program Problem
}

National Cancer Institute

\section{Source}

National Cancer Institute. Application Program Problem. NCI Thesaurus. Code C63305.

Problem associated with the requirement for software to fulfill its function within an intended use or application. 